\title{
The Modification Design of Low-noise Locomotive Traction Gear
}

\author{
Jianping / SUN \\ School of Railway Transportation \\ East China Jiao Tong University \\ Nanchang Jiangxi, China \\ e-mail: sunjianping@ecjtu.jx.cn \\ Zhaoping / TANG \\ School of Information Engineering \\ East China Jiao Tong University \\ Nanchang Jiangxi, China \\ e-mail: tzp@ecjtu.jx.cn
}

\author{
Zhongwei / LIU \\ CSR Qishuyan Locomotive \& Rolling Stock \\ Technology Research Institute Co., Ltd. \\ China CSR Qishuyan Institute Co., Ltd. \\ Changzhou Jiangsu, China \\ e-mail: liuzhongwei@sina.com
}

\author{
Xinjian / ZHOU \\ School of Mechanical \&Electrical Engineering \\ East China Jiao Tong University \\ Nanchang Jiangxi, China \\ e-mail: zhouxinjian@ ecjtu.jx.cn
}

\begin{abstract}
The design method and design criteria for low noise gear were introduced. Based on the analysis of gear modification principle, determination of basic parameters and the design of modification scheme, taking SS8- II type quasi- high speed passenger electric locomotive gear transmission as a studying example, the gear tooth profile modification and axial modification were designed. Through the noise detection, it was found that under the same conditions, the driving device noise sound level A can reduce the $6 \sim 10 \mathrm{~dB}$ after modifying. It achieved better noise reduction effect, which can provide reference for the design of low noise gear. It has important value for engineering practice.
\end{abstract}

Keywords- locomotive traction gear; low-noise gear; gear modification; modification design; parameters

\section{INTRODUCTION}

Due to the comprehensive deformation amount caused by loading, gear transmission error, time varying meshing stiffness, elastic deformation of tooth and gear body, high speed running thermal deformation and the system deformation, the tooth static conjugate tooth profile's equilibrium conditions are destroyed along the meshing line. Furthermore, the intense vibration and noise will be produced in the transmission [1-3]. The design method and the criteria for most of low noise gear mainly focus on controlling and reducing the source of gear internal incentive, that is, the degree of contact state in meshing process deviates from the ideal state, among which the key is the contact surface shape difference [4-6]. The existing experimental and theoretical analysis show that, under heavy load, high speed, fully consistent with the theoretical tooth shape of gear, the transmission performance can't achieve the optimal [7].The reasonable tooth shape not only can effectively reduce the vibration and noise caused by the internal motivation, but also can uniform tooth width load, improve the tooth surface stress distribution, increase the bearing capacity, effectively reduce the unit load under constant torque[8]. Therefore, without affecting the other aspects (such as intensity), gear modification becomes one of the most important means to reduce gear vibration and noise and to improve gear transmission reliability under high speed and heavy load.

\section{GEAR MODIFICATION PRINCIPLES}

Gear modification is to modify consciously the tooth surface in micro scale, so as to the tooth surface deviations from the theory. It was divided into profile modification and axial modification. Profile modification is to remove a part of the material along the direction of the tooth high. By changing the tooth profile, the impact of meshing into and out is reduced due to elastically deforming. Axial modification is to modify gear along tooth width direction. It can compensate tooth deviation due to twisting and bending deformation form the support shaft and gear tooth; eliminate of the partial load and improve the carrying capacity and the reliability of gear. Research showed that: the axial modification can reduce transmission noise 2-8 dB; profile modification can reduce transmission noise $5 \mathrm{~dB}$ (especially suit for straight gear transmission).

\section{A. Profile modification}

Profile modification includes tip and root relief, pressure angle modification and drum corrected profile (Fig .1). Tip and root relief is the most common application of tooth profile modification. The principle is to backward retract tip and root positions of the involutes which are easy to produce the impact when gear engaged. The pressure angle modification is can compensate for the tooth profile deformation error of gear pair when single tooth meshing stiffness is small or tooth profile overall deformation is large by increasing or decreasing the pressure angle. In order to make the contact spot in the middle of tooth profile, that from the end face tooth profile, to extend a fixed point (usually the pitch circle) toward the addendum and dedendum, and gradually increase the cuts, until it reaches the meshing starting point of addendum and dedendum is 
called drum corrected profile.

In Fig .1, $d_{C a}$ and $d_{C f}$ are respectively addendum and dedendum circle diameter of relief starting; $C_{\alpha a}$ and $C_{\alpha f}$ are respectively the tip and root relief amounts; $L_{C a}$ and $L_{C f}$ are respectively the meshing line length of corresponding the height of tip and root relief; $C_{H \alpha}$ is slope amount of the entire tooth surface; $C_{\beta}$ is the amounts of drum corrected profile.
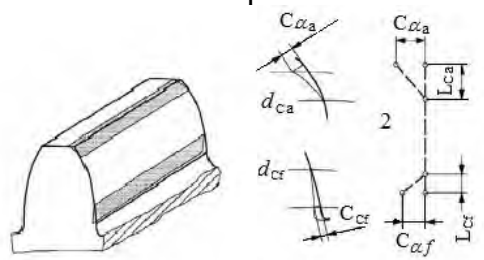

(a)

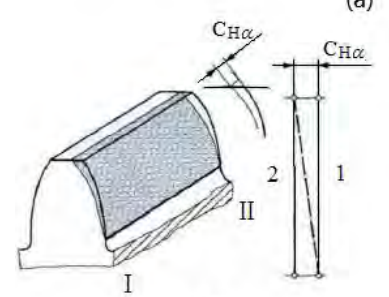

(b)

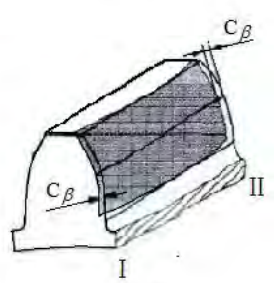

(c)
Figure 1. (a) tip and root relief (b) pressure angle modification (c) drum corrected profile

\section{B. Axial modification}

Axial modification includes end relief, crowning axial modification and spiral angle modification (Fig .2). End relief is to gradually thin the tooth thickness in a stub of tooth width toward one end or two ends of gear, so as to avoid the stress concentration which is produced by the "edge effect" in meshing, improve high local stress situation on tooth surface. Spiral angle modification is to micro- change helix angle size, so as to compensate total helix angle error which is caused by mismachining tolerance, the box bearing hole slope and the parallelism error, bearing inner and outer diameter concentricity error and gear shaft center line parallelism error, and well as local helix angle error which is caused by gear shaft bending and torsion deformation and thermal deformation for the uneven temperature. The crowning axial modification is correct the tooth width as drum shape, i.e. the middle is concave and two ends is symmetrical. It can compensate the transmission shaft bending deformation and optimize the gear contact spots after loading.

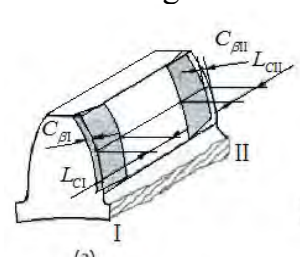

(b)

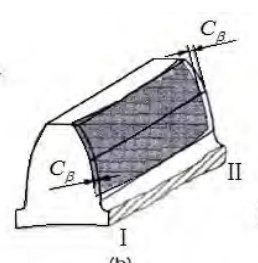

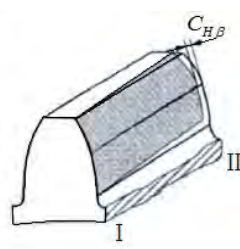

Figure 2. (a) end relief (b) crowning axial modification (c) helix angle modification
In Fig .2, $C_{\beta \mathrm{I}}$ and $C_{\beta \mathrm{II}}$ are respectively, end relief amounts of tooth end I and II; $L_{\mathrm{CI}}$ and $L_{\mathrm{CII}}$ are respectively end relief length of tooth end I, II 1; $C_{\beta}$ is the arc height of after the drumming; $C_{H \beta}$ is the final modification amount of helix angle.

\section{BASIC MODIFICATION PARAMETERS}

\section{A. Basic parameters of the profile modification}

The profile modification basic parameters include modification amount, length of modification and the modification curve. Modification amount has many computational methods. It is theoretically equal to elastic deformation of two teeth when single and double tooth mesh alternately. In order to compensate the influence of gear machining error, they should be considered into such as the base pitch error, the tooth profile error etc. Because many factors affect the modification amount, accurate calculation is relatively complex; experience formula after simplified mainly is used in practical application. Table 1 lists the GB recommended formula.

TABLE I. THE CALCULATION FORMULA FOR TOOTH PROFILE MODIFICATION AMOUNT, UNIT ( $\mu m$ )

\begin{tabular}{|l|c|l|}
\hline $\begin{array}{c}\text { The upper limit or lower } \\
\text { limit of tolerances }\end{array}$ & $\begin{array}{c}\text { The starting point of } \\
\text { meshing }\end{array}$ & \multicolumn{1}{c|}{$\begin{array}{c}\text { The end point of } \\
\text { meshing }\end{array}$} \\
\hline Straight gear pair & $\Delta_{1 u}=7.5+0.05 W_{t}$ & $\Delta_{2 u}=0.05 W_{t}$ \\
& $\Delta_{1 o}=15+0.05 W_{t}$ & $\Delta_{2 o}=7.5+0.05 W_{t}$ \\
\hline Helical gear pair & $\Delta_{1 u}=5+0.05 W_{t}$ & $\Delta_{2 u}=0.04 W_{t}$ \\
& $\Delta_{1 o}=13+0.04 W_{t}$ & $\Delta_{2 o}=5+0.04 W_{t}$ \\
\hline
\end{tabular}

Note: $W_{t}$ is the load per unit tooth width, $N / \mathrm{mm}$.

Modification lengths include the long modification. In order to ensure the continuous transmission, it should ensure that the gear pair overlap degree is higher than 1 after modifying. Therefore, modification length's limit points are respectively a starting point and end point to guarantee a pitch length. Short modification must be able to guarantee that end overlap degree is 1 , so as to effectively reduce the impact as meshing into or out. Long modification's modification lengths are respectively along the involutes, and extend single tooth meshing and the lowest point and the highest point, so as to effectively reduce the rotational position deviation.

Long modification can make load smooth transition in meshing alternation of single and double teeth. It is commonly used in the large gear width, large helix angle helical gear tooth profile modification. However, for straight gear and routine helical gear modification, the overlap degree will be decreased after modifying. It is easy to cause vibration and noise for the discontinuity meshing, so the short modification is generally used. The modification length $l$ can be gotten, as in (1):

$$
l=\left(Z-P_{b}\right) / 2
$$

In (1): $Z$ is the length of Line of action; $P_{b}$ is the 
pitch length.

The modification curve is generally expressed as the power function form, as in (2):

$$
\mathrm{V}=\mathrm{V}_{\max }\left(\frac{x}{l}\right)^{b}
$$

In (2), $x$ is the relative coordinate of engaging position; $l$ is the length of modification; $\mathrm{V}$ is the corresponding modification amount of $x$; power index is $1-2$. When $b=1$, it is equivalent to the linear modification. It can't smoothly connect with the tooth profile modification curve, and impact seriously tooth surface meshing on gear drive in light load. When $b=2$, the curve uses a parabola, it will have a smooth transition between the curve and the tooth profile, and it helps to reduce the impact of tooth surface meshing.

\section{B. Basic parameters of axial modification}

\section{1) For End relief:}

Quenching and tempering gear:

$$
C_{\beta} \approx f_{s h}+1.5 f_{H \beta}+(5 \sim 10) \mu m
$$

Surface hardening and nitriding gear:

$$
C_{\beta} \approx 0.5\left(f_{s h}+1.5 f_{H \beta}\right)+(5 \sim 10) \mu m
$$

In (3) and (4), $f_{s h}$ is the axial meshing error component for comprehensive deformation; $f_{H \beta}$ is the axial meshing error component for gear manufacturing and installation. For high speed gear of the high accuracy and high reliability, End relief amount takes the $60 \%-70 \%$ calculated value. The width of end relief takes the smaller value of $0.1 B$ ( $0.1 B$ is tooth width) and $2.0 m_{n}\left(m_{n}\right.$ is the normal module). End relief curve can be straight or arc along tooth width direction.

\section{2) Crowning axial modification.}

There are two main methods on the crowning axial modification calculation: one is based on experience, i.e. directly gives the reference value, as in (5); the other is the use of theory formula. In addition, the finite element method also has obtained the certain effect of modification. In the ISO standard, drum quantity of ordinary gear is $10 \leq C_{\beta} \leq 40 \mu \mathrm{m}$.

$$
C_{\beta} \approx 0.5\left(f_{s h}+f_{H \beta}\right) \mu m
$$

\section{3) Helix angle modification.}

The key of helix angle modification is to determine the modification amount. The process of solving the best modification amount is actually an optimization problem. Generally the optimal value can be determined through the finite element model, optimization analysis on of load distribution of tooth surface meshing process.

\section{THE DESIGN OF MODIFICATION SCHEME}

Wang Cheng [9] thought that it is easy to emerge pitting corrosion in the root side near the gear's pitch line. So hardened gear tooth usually adopted only tip modification. Considered from the processing economic aspect, the general choice was small gear total tooth profile modification, and the big matching gear didn't do the modification. Huo Zhaobo achieve the idea noise reduction effect through testing directly the vibration and noise under different gear profile modification parameters, analyzing and research the influence of different modification scheme for vibration and noise, and optimizing the design of noise reduction.

Shang Zhenguo [10] determined the best combination on modification amount, modification curve shape of addendum, dedendum and helix angle modification between two mating gears, by analyzing contact trace of driving and driven gear under a variety of modification parameter combinations method. Imerk [11] used test method to compare the gear meshing with axial modification or not, and analyzed the instantaneous distribution of contact stress and tooth surface wear. His results showed that the axial modification could make the tooth surface contact stress is approximately uniform distribution in the tooth width direction, and its value was smaller than no-modification. In addition, the modification reduced the contact stress peak value at the turn of the single and double teeth, and reduced the vibration and noise.

In the existing research on modification schemes aimed at reducing vibration and noise, the most took the minimal transmission error fluctuations, dynamic meshing force, tooth surface load density minimum as objective. However, although the meshing gear noise was mainly caused by the dynamic meshing force and other parameters, but also it related to the body structure, natural frequency, vibration type, the transfer characteristics input between them. Bahk [12] took the minimal fluctuations of gear transmission error and the minimal vibration response as optimization objective function of gear modification. He found that both had large difference in the optimum modification amount, which amended the traditional strong correlation assumption about between static error and dynamic response. So it is necessary to use precision sound level meter for gear noise acquisition, and directly analyze effect of noise reduction and evaluate performance. And on this basis, further through the experiment and research on the establishment of direct mapping relation between modification parameters and vibration noise, the studies will provide a basis for seeking optimum strategies of gear noise control.

\section{FOR EXAMPLE}

Taking SS8- II type quasi high speed passenger electric locomotive gear transmissions as an example, the parameters were shown as follow. Single shaft power: $\mathrm{P}=900 \mathrm{~kW}$; motor speed in high-speed operation: $\mathrm{n}=1946 \mathrm{r} / \mathrm{min}$; modulus of gear $m=12$; tooth number of driving gear $z_{1}=31$, tooth number of driven gear $z_{2}=$ 77; pressure angle $\alpha=22.5^{\circ}$; the meshing angle $\alpha^{\prime}=$ $22.9219^{\circ}$; center distance $a^{\prime}=650 \mathrm{~mm}$. The driving gear displacement factor $x_{1}=0.10184$; The driven gear 
displacement factor $x_{2}=0.0663$. The addendum chamfering coefficient of the driving and driven gear $\mathrm{Vh}_{1} 、 \mathrm{Vh}_{2}$ are respectively 112 and 120 ; their materials are respectively 20CrMnMoA (carburizing and quenching) and the $15 \mathrm{CrNi6}$ (nitriding and quenching).

\section{A. The modification scheme}

Profile modification of the driving and driven gear all adopted tip and root relief in meshing district of two gears, and a short modification way by guaranteeing the end face overlap ratio was 1 , so as to effectively reduce the impact of meshing into and out.

Because the transmission speed was high, the axial deformation is large, considering the contact phenomenon of the alternate increased stress of two gear tooth ends in running, and in order to avoid the "edge effect", end relieves was adopted at the both ends of two gear.

\section{B. The tip or root relief and the modification length}

Because that the tooth shape error was evaluated should be for its work part, firstly, gears' $\mathrm{K}$ shape chart parameters should be determined, such as the starting point of effective meshing, the end point of effective meshing and the pitch diameter. In actual measurement, according to the different instruments, each point were represented as the expanding the length or angle. Gears meshing were shown in the Fig .3.

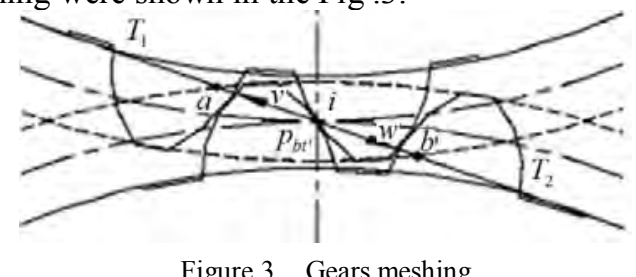

Figure 3. Gears meshing

In Fig .3, $i$ was the common tangent points of two gear pitch circle; $T_{1} T_{2}$ was the length of theoretical line of action; $a b$ was the length of actual line of action; $T_{1} a$ and $T_{2} b$ were respectively the expansion length of the starting points of effective meshing of gear 1 and gear $2 ; T_{1} v$ and $T_{2} w$ were respectively the expansion length of the root relief limit points on gear 1 and gear $2 ; T_{1} w$ and $T_{2} v$ were respectively the expansion length of the tip relief limit points on gear 1 and gear $2 ; T_{1} b$ and $T_{2} a$ were respectively the expansion length of the end points of effective meshing of gear 1 and gear 2 .

1) The theoretic meshing line length:

$\mathrm{g}_{12}=T_{1} T_{2}=a^{\prime} \sin \alpha_{\omega t}=650 \sin 22.9219=253.1591$

2) The pitch diameter $(O P D)$ expansion length:

$$
\begin{gathered}
\mathrm{g}_{1 i}=T_{1} i=0.5 O P D_{1} \sin \alpha_{\omega t}=72.6660 \\
\mathrm{~g}_{2 i}=T_{2} i=0.5 O P D_{2} \sin \alpha_{\omega t}=180.4930
\end{gathered}
$$

3) The pitch diameter (OPD) expansion angle:

$$
\begin{aligned}
& \theta_{1 i}=57.29 T_{1} i /\left(d_{b 1} / 2\right)=24.2260^{\circ} \\
& \theta_{2 i}=57.29 T_{2} i /\left(d_{b 2} / 2\right)=24.2260^{\circ}
\end{aligned}
$$

4) The expansion length of effective mesh end point $(S A P)$ :

$$
\begin{gathered}
\mathrm{g}_{1 b}=T_{1} b=\sqrt{\left(\mathrm{d}_{a 1}-2 \mathrm{~V}_{h 1}\right)^{2}-\mathrm{d}_{b 1}^{2}} / 2=99.9164 \\
\mathrm{~g}_{2 a}=T_{2} a=\sqrt{\left(\mathrm{d}_{a 2}-2 \mathrm{~V}_{h 2}\right)^{2}-\mathrm{d}_{b 2}^{2}} / 2=208.8848
\end{gathered}
$$

5) The expansion angle of effective mesh end point $(S A P)$ :

$$
\begin{aligned}
& \theta_{1 b}=57.29 T_{1 b} /\left(d_{b 1} / 2\right)=33.3110 \\
& \theta_{2 a}=57.29 T_{2 a} /\left(d_{b 1} / 2\right)=28.0368
\end{aligned}
$$

6) The expansion length of effective mesh starting point $(S A P)$ :

$$
\begin{aligned}
& \mathrm{g}_{1 a}=T_{1} a=T_{1} T_{2}-T_{2} a=44.2743 \\
& \mathrm{~g}_{2 b}=T_{2} b=T_{1} T_{2}-T_{1} b=153.2427
\end{aligned}
$$

7) The expansion angle of effective mesh starting point $(S A P)$ :

$$
\begin{aligned}
& \theta_{1 a}=57.29 T_{1 a} /\left(d_{b 1} / 2\right)=14.7605 \\
& \theta_{2 b}=57.29 T_{2 b} /\left(d_{b 2} / 2\right)=20.5684
\end{aligned}
$$

8) The expansion length of addendum modification limit point $(S B P)$ :

$$
\begin{aligned}
& \mathrm{g}_{1 w}=T_{1} w=T_{1} i+p_{b t} / 2=91.5738 \\
& \mathrm{~g}_{2 v}=T_{2} v=T_{2} i+p_{b t} / 2=199.4008
\end{aligned}
$$

9) The expansion angle of addendum modification limit point $(S B P)$ :

$$
\begin{aligned}
& \theta_{1 w}=57.29 T_{1} w /\left(d_{b 1} / 2\right)=30.5296 \\
& \theta_{2 v}=57.29 T_{2} v /\left(d_{b 2} / 2\right)=26.7638
\end{aligned}
$$

10) The expansion length of tooth root modification limit point $(S B P)$ :

$$
\begin{gathered}
\mathrm{g}_{1 v}=T_{1} v=T_{1} i-p_{b t} / 2=53.7583 \\
\mathrm{~g}_{2 w}=T_{2} w=T_{2} i-p_{b t} / 2=161.5853
\end{gathered}
$$

11) The expansion angle of tooth root modification limit point $(S B P)$ :

$$
\begin{gathered}
\theta_{1 v}=57.29 T_{1} v /\left(d_{b 1} / 2\right)=17.9224 \\
\theta_{2 w}=57.29 T_{2} w /\left(d_{b 2} / 2\right)=21.6882
\end{gathered}
$$

According to table 1 , by calculating, the profile modification tolerance upper and lower bounds of the meshing starting point on the smaller gear are respectively 11.6710 and $19.1710 \mu \mathrm{m}$, meshing end point's are respectively 4.1710 and $11.6710 \mu \mathrm{m}$.The profile modification tolerance upper and lower bounds of the meshing starting point on the bigger gear are respectively11.8524 and $19.3524 \mu \mathrm{m}$, meshing end point's are respectively 4.3524 and $11.8524 \mu \mathrm{m}$.

Taking the tip relief of the smaller gear as $16 \mu \mathrm{m}$, root relief as $6 \mu \mathrm{m}$, tooth shape tolerances as $20 \mu \mathrm{m}$, and taking the tip relief of the bigger gear as $16 \mu \mathrm{m}$, root relief as $6 \mu \mathrm{m}$, tooth shape tolerances as $24 \mu \mathrm{m}$, the tolerance zones of the two gears' profile modification ( $\mathrm{K}$ shape chart) were shown in Fig .4.

By (1), the modification length could be gotten:

$$
l=\left(Z-P_{b}\right) / 2=46.2085
$$

The modification curve used the formula which was 
proposed by Webber, i.e. $\mathrm{b}=1.5$. By (2), $\mathrm{V}=16\left(\frac{x}{l}\right)^{1.5}$ could be gotten. By using Matlab, the modification curve was drawn as shown in Fig .5.

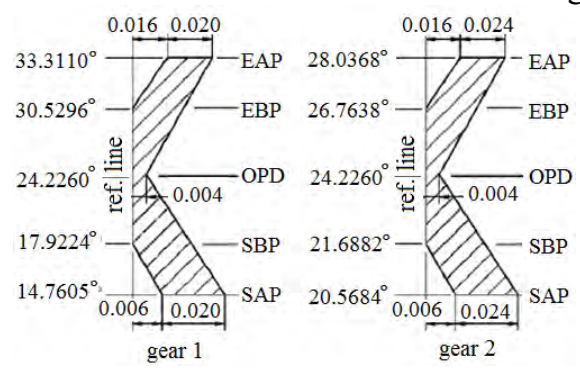

Figure 4. The tolerance zone of driving gear modification and driven gear modification

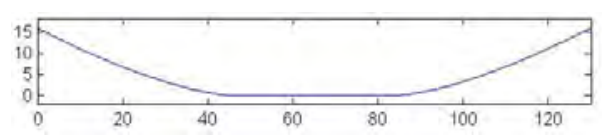

Figure 5. The modification curve

\section{The thinned amount results of the tooth end and the slope length}

Through calculating, both the end relief amount of gear 1 and gear 2 were $10 \mu \mathrm{m}$, both the width of end relief were $12 \mathrm{~mm}$ (about 0.1 times as the width of teeth). The end relief amount and tolerance zones of two gears were shown in Fig .6.

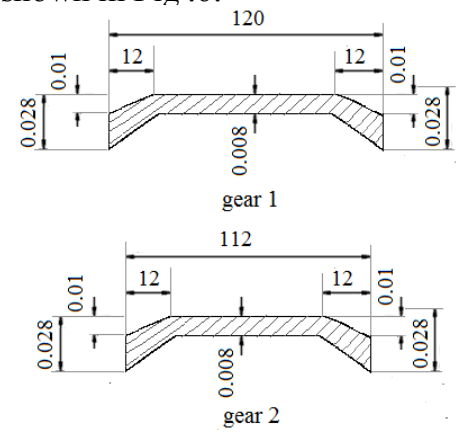

Figure 6. The thinned amount results of the tooth end

\section{Detection and assessment of noise}

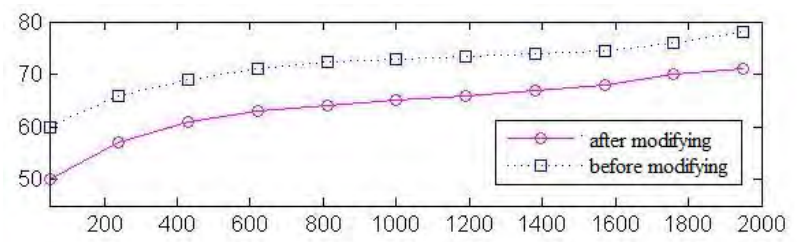

Figure 7. Noise results comparing before and after modifying

After checking, about the design scheme of modification of traction gear transmission, the tooth surface contact fatigue strength, bonding strength and root bending fatigue strength can meet the requirement. To test and compare the noise of SS8- II type passenger electric locomotive wheel driving device before and after modifying, under the same conditions, the tests found that the sound level A of driving device noise could reduce $6 \sim 10 \mathrm{~dB}$ after modifying (Fig .7).

\section{CONCLUSIONS}

Reasonable gear modification scheme and parameters can reduce the vibration and noise, improve the gear contact characteristics, as well as improve the load - carrying capacity and operation reliability. However, at present, the related research on gear modification noise reduction is mainly the common research on gear. It still need to strengthen about how to further distinguish the different characteristics of actual working conditions, such as the low speed, high speed, light load and heavy load, targeted design, get the best modification effect.

\section{ACKNOWLEDGEMENT}

This work was funded by Chinese Nature Science Foundation (NO.51465017).

\section{REFERENCES}

[1] Smith, J.Derek. Gear Noise and Vibration [M]. CRC Press, 2003.

[2] Tugan Eritenela, Robert G. Parker, "Three-dimensional nonlinear vibration of gear pairs," Journal of Sound and Vibration, vol. 331, July 2012, pp. 3628-3648, doi: 10.1016/j.jsv.2012.03.019.

[3] Zhu P, Xieeryazidan A, Zhang H X, "Research on the Relationship between End Processing Technology and Processing Quality of Spiral Bevel Gear ," Key Engineering Materials, vol. 522, August 2012, pp. 31-35, doi 10.4028/www.scientific.net/ KEM.522.31.

[4] Yi-Pei Shih, " A novel ease-off flank modification methodology for spiral bevel and hypoid gears," Mechanism and Machine Theory, vol. 45, August 2010, pp. 1108-1124, doi: 10.1016/j.mechmachtheory.2010.03.010.

[5] Tugan Eritenel, Robert G, " Parker. An investigation of tooth mesh nonlinearity and partial contact loss in gear," Mechanism and Machine Theory, vol.56, October 2012, pp. 28-51, doi 10.1016/j.mechmachtheory.2012.05.002.

[6] Chang, L., Jeng, Y.-R., and Huang, P.-Y., Discussion "Modeling and Analysis of the Meshing Losses of Involute Spur Gears in High-Speed and High-Load Conditions," Journal of Tribology, vol. 135, Dec , 2012, pp. 011504, doi: $10.1115 / 1.4007809$.

[7] Wu Y, Wang J, Han Q, "Static/dynamic contact FEA and experimental study for tooth profile modification of helical gears," Journal of mechanical science and technology, vol. 26 , May 2012, pp. 1409-1417, doi: 10.1007/s12206-011-1028-1.

[8] TANG Zhaoping, SUN Jianping, "The Accurate Parametric Design and Assembly Simulation of the Spread Blade Cylindrical Gears with Curvilinear Tooth Ttace," Machine tool \& Hydraulics, vol. 38 ,Oct. 2010 , pp. 108-111, doi:10.3969/j. issn.1001-3881.2010.19.031.

[9] Wang Cheng, Fang Zongde, Jia Haitao, Zhang Junhui, “ Modification optimization of double helical gears," Journal of aerospace power, vol. 24 ,June 2009 , pp. 1432-1436, doi: 1000-8055(2009)06-1432-0.

[10] Shang Zhenguo, Wang Delun, "Analysis of modification of helical gears meshing characteristics and error influence," Journal of Dalian University of Technology, vol.51,.March 2011, pp.368-374, doi: 1000-8608(2011)03-0368-07.

[11] Imrek H, Düzcükoglu H, "Relation Between Wear and Tooth Width Modification in Spur Gears ," Wear, vol. 262,February 2007 , pp. 390-394, doi: 10.1016/j.wear.2006.06.004.

[12] Bahk C J, Parker R G, "A Study on Planetary Gear Dynamics With Tooth Profile Modification," In ASME 2011 International Design Engineering Technical Conferences and Computers and Information in Engineering Conference. American Society of Mechanical Engineers, Washington, DC, USA, August 2011, pp. 365-377, doi: 10.1115/DETC2011-47346 